SUICIDE ATTEMPTS IN TURKISH UNIVERSITY STUDENTS:

THE ROLE OF COGNITIVE STYLE, HOPELESSNESS, COGNITIVE

REACTIVITY, RUMINATION, SELF-ESTEEM, AND PERSONALITY TRAITS

\begin{abstract}
Esma Akpinar Aslan ${ }^{1 *}$, Sedat Batmaz ${ }^{1}$, Mesut Yildiz $^{2}$, Emrah Songur $^{3}$
\end{abstract}
${ }^{1}$ Department of Psychiatry, School of Medicine, Tokat Gaziosmanpasa University, Tokat, Turkey.

${ }^{2}$ Department of Psychiatry, School of Medicine, Marmara University, Istanbul, Turkey.

${ }^{3}$ Psychiatry Clinic, Kecioren Training and Research Hospital, Health Sciences University, Ankara, Turkey.

Running Title: Cognitive Profile of Suicide Attempters

Total word count (excluding abstract, references, tables): 6349

*Correspondence:

Esma Akpinar Aslan, Department of Psychiatry, School of Medicine, Tokat Gaziosmanpasa University, Tokat, Turkey.

Phone: +90 (356) 2149444 - 1054

e-mail: esma.akpinaraslan@gop.edu.tr

ORCID ID:

Esma Akpinar Aslan: https://orcid.org/0000-0003-4714-6894

Sedat Batmaz: https://orcid.org/0000-0003-0585-2184

Mesut Yildiz: https://orcid.org/0000-0001-6964-6705

Emrah Songur: https://orcid.org/0000-0003-4949-0154 


\title{
SUICIDE ATTEMPTS IN TURKISH UNIVERSITY STUDENTS: THE ROLE OF COGNITIVE STYLE, HOPELESSNESS, COGNITIVE REACTIVITY, RUMINATION, SELF-ESTEEM, AND PERSONALITY TRAITS
}

\begin{abstract}
Background: Suicide is one of the major public health problems in young adults. Detecting the risk factors and correlates among university students might help identify students who are under risk and who need early interventions for suicide prevention.
\end{abstract}

Aims: The current study aimed to investigate the cognitive style, self-esteem, hopelessness, rumination, cognitive reactivity, and personality characteristics of Turkish university students, who previously attempted suicide and who did not.

Method: A total of 355 university students (34 previous suicide attempters) were recruited for this study, and they completed the Ten-Item Personality Inventory (TIPI), the Ruminative Response Scale (RRS), the Leiden Index of Depression Sensitivity-Revised (LEIDS-R), the Beck Hopelessness Scale (BHS), the Cognitive Style Questionnaire-Short Form (CSQ), the Rosenberg Self-Esteem Scale (RSES), and the Hospital Anxiety and Depression Scale (HADS).

Results: Higher RRS, BHS, CSQ scores and lower TIPI-A and RSES scores were significantly associated with a previous suicide attempt.

Conclusion: Negative cognitive style, hopelessness, and rumination were significant correlates of a previous suicide attempt. These cognitive factors may be targets in psychotherapy to reduce suicide attempts in college-age individuals.

Keywords: cognitive style, hopelessness, rumination, suicide attempt, university students

\section{INTRODUCTION}


Suicide is a major public health problem which impacts individuals, families, and communities, and almost one million people die by suicide each year worldwide (World Health Organization; WHO 2012). According to the World Health Organization (WHO) data, the annual global agestandardized suicide rate was 11.4/100.000 (8.0/100.000 for women and 15.0/100.000 for men) in 2012, whereas for Turkey age-standardized suicide rates were 4.2/100.000 for women and 11.8/100.000 for men (WHO 2014). In Turkey, according to the data of the Turkish Statistical Institute (TSI), the crude suicide rate was 4.11/100.000 $(2.25 / 100.000$ for women and 5.95/100.000 for men) in 2015 (Turkish Statistical Institute 2015). The difference between the TSI and the WHO data is due to the fact that the data of the TSI is not standardized according to age.

Specifically, college is a time of increased independence for young adults, and often entails waning parental support and consequently, a large proportion of students feel lonely, stressed, inadequate, anxious, and depressed. A large study showed that mental disorders were common among college students, had onsets that mostly occurred prior to college entry, and were typically untreated (Auerbach et al. 2016). Further, between $9 \%$ to $25 \%$ of college students reported suicidal ideation or behaviour (i.e., plan, intent, and/or attempts) (Becker et al. 2018; Drum et al.2009; Holdaway et al. 2018). These high rates of suicidal behaviours have been alarming, and it has been suggested that the first onset of suicidal thoughts and behaviours in college appears to be higher than in the general population (Mortier et al. 2017). Another study pointed out that about $75 \%$ of suicidal thoughts and behaviours started before the age of 16 , and that more than the half $(53.4 \%)$ of lifetime suicide ideators transitioned to a suicide plan whereas almost a quarter $(22.1 \%)$ of lifetime suicide planners transitioned to an attempt (Mortier et al. 2018a). Another study, on the other hand, proposed that college students had a significantly lower rate for suicidal thoughts and behaviors compared to their same-aged peers, but also demonstrated that any suicidality before the age of 18 was associated with reduced 
likelihood of college entrance as well as greater attrition from college (Mortier et al. 2018b). Transcultural comparisons between Turkish and American youth provided a differential vulnerability for and risk factors of suicide patterns (Coskun et al. 2012). These differences need to be investigated more thoroughly, and evaluating these factors among college-age youth may help identify and ameliorate suicide risk among Turkish young adults.

The term suicide encompasses a broad spectrum ranging from wish to die, suicidal ideation, suicidal plans, suicide attempts to suicide death (Bakhiyi et al. 2016). Suicidal ideation, thought or desire to end one's own life, is associated with suicide attempts (Sarkisian et al. 2019). Suicide attempt is defined as a non-fatal, self-directed, potentially injurious behavior with an intent to die as a result of the behavior, but that may or may not result in injury (Crosby et al. 2011).)As many more individuals experience suicidal ideation than go on to make suicide attempts, examining factors that may be differentially related to suicidal ideation and attempts is a significant public health priority. Moreover, these experiences seem to be temporally associated. De Leo et al. (2005) for example, showed that over 99\% of suicide attempters planned their attempt or experienced suicidal ideation before their attempt and that over 50\% of individuals who reported suicidal ideation or behaviour experienced all levels of 'less severe' suicidal thoughts and behaviours preceding their most severe experience (e.g.life not worth living, seriously considering suicide) (Butter et al. 2019). Non-suicidal self injury which can be defined as self-inflicted damage to one's self that lack evidence of suicidal intent, and suicidal ideation have each been shown to confer risk for suicidal attempts (Ribeiro et al. 2016); Washburn et al. 2012)There are many studies aimed to search the relationship between these entities and evaluate the risk factors. In a recent study, 456 adolescents who reported suicidal thoughts and 569 who reported non-suicidal self-harm at 16 years of age were included. Logistic regression analyses were used to explore associations between a wide range of prospectively recorded risk factors and future suicide attempts, assessed at the age of 21 years. 
Among participants with suicidal thoughts, the strongest predictors of transition to attempts were non-suicidal self-harm, cannabis use, other illicit drug use, exposure to self-harm (family, and higher levels of the personality type intellect/openness. Among participants with nonsuicidal self-harm at baseline, the strongest predictors were cannabis use, other illicit drug use, sleep problems, and lower levels of the personality type extraversion (Mars et al. 2019). According to the results of a study which was conducted on 45 patients with suicide attempt or self-harm admitted to emergency department, the predictive factors of suicide attempt and selfharm were as follow: family function, hopelessness, and non-suicidality items of Hamilton scale, history of non-suicidal self-harm, and anxiety (Salman et al. 2014), .In a more recent case-control study compared 55 cases of suicide attempt within the previous 12 months matched for age and sex with 55 nonsuicidal cases the results showed that borderline PD and depressive disorder predicted increased likelihood of future suicide attempts (Wongpakaran et al. 2019). Many different theories of suicide have been proposed, including biological, sociological, and psychological proposed etiologies (Franklin et al. 2017). Previous research has already defined risk factors for suicidal behaviours in adolescence and young adulthood: (i) Individual-level factors, for example, gender, genetic traits (personality traits, cognitive styles), mental health, previous suicidal behaviour, alcohol or substance abuse. (ii) Familial factors, for example, family history of suicide, trauma or mental illness. (iii) Life stressors, for example, death of a parent, family breakdown, physical or sexual abuse, bullying. (iv) Social-environmental and demographic factors, for example, lower socioeconomic status, rural residence (Borschmann et al. 2018; Waldvogel et al. 2008). Specific disorders with a strong relation to suicide include depression and other mood disorders, anxiety disorders, personality disorders, alcohol and drug use disorders, and schizophrenia (Assari et al. 2018). The presence of a psychiatric disorder and particularly major depressive disorder is a risk factor for suicide across all age groups (Prigerson et al. 2003). 45\% of inpatient suicides were preceded by schizophrenia and organic 
mental disorders, whereas $32 \%$ of outpatients' suicides occurred in the context of depression, and substance-related, somatoform, anxiety, and adjustment disorders (Bachmann 2018, Bertolote et al. 2003). Individuals with bipolar spectrum disorders experience high rates of suicide with previous reports indicating that 25 to $50 \%$ of individuals with bipolar I or II disorder have a lifetime history of a suicide attempt (Leverich et al. 2003;Stange et al. 2015; Valtonen et al. 2005), and twenty to thirty times greater risk than the general population (Pompili et al., 2013).

Maladaptive cognitions play an important role in depression and anxiety disorders and also in suicidal ideation or attempt. A depressogenic attributional/cognitive style, for example, may lie behind depressive as well as suicidal (mediated by hopelessness) cognitions, and this cognitive style of thinking may be defined as a tendency to associate negative life events to internal, stable, and global factors. Individuals with this style of thinking infer that negative consequences will follow from current negative events, and they believe that the occurrence of negative events means that the self is flawed (Abramson et al. 2002; Rickelman and Houfek 1995). Conclusions from a literature review on 21 studies lent support to the effect of depressogenic cognitive style on depressed mood in children and adolescent (Jacobs et al. 2008).Further, negative inferential styles were suggested to be positively associated with suicidal ideation (Kleiman et al. 2014).Theoretical models of suicide have suggested that making negative appraisals about the future following stressful life events may facilitate the progression of feelings of entrapment toward suicide ideation (Malhi et al. 2013; Stange et al. 2015). Findings from a study conducted on adolescent suicide attempters revealed that this group have a cognitive style that promotes a more negative evaluation of events and situations (Kienhorst et al. 1992).

Hopelessness is defined as "a system of cognitive schemas whose common denominator is negative expectations about the future" (Beck et al. 1974, p. 864), or a "lowered expectation of 
obtaining certain goals and a diminished belief in the likelihood of achieving success" (Melges and Bowlby 1969). Hopelessness has an important role in the aetiology of depression, and it may also be a predictor of suicide. In some prospective studies, a correlation was shown between hopelessness, suicidal ideation and depression (Beck et al. 1974; Chioqueta and Stiles 2003).Individuals with depression and higher levels of hopelessness, since not all individuals with depression experience feelings of hopelessness, report higher levels of suicide intention (Beck et al. 1985). Several studies have found a strong association between hopelessness and attempted suicide or death through suicide (Beck et al. 1990; Jaiswal et al. 2016; Klonsky et al. 2012). Moreover, a 10-year cohort study showed that a given assessment of hopelessness (baseline, 6-months, 24-months, and 48-months) reliably predicted attempted suicide up to 46 years later (Klonsky et al. 2012). Hopelessness has been independently and repeatedly associated with increased risk for suicidal ideation, suicide attempts, and death by suicide, both prospectively and retrospectively (Hewitt et al. 1998; Mccullumsmith et al. 2014; Samuelsson et al. 2006). Hopelessness has also been implicated in exacerbating the influence of other known factors for suicide (Steeg et al. 2016). Thus, the assessment of hopelessness is particularly important in clinical practice, as it can lead to isolation, or may inhibit help-seeking behaviors. Recognizing high levels of hopelessness in patients is rather important, as hopelessness is a modifiable risk factor whose impact can be reduced through appropriate psychotherapeutic interventions (Aloba et al. 2015; Efstathiou et al. 2018).

How easily maladaptive cognitions may be triggered by low mood even if the mood state is not pathological may be referred to as cognitive reactivity (CR) (Antypa et al. 2010).Previous research demonstrated that CR measured by the Leiden Index of Depression SensitivityRevised (LEIDS-R) (Van der Does 2002) differentiated between previously depressed and never depressed individuals (Van der Does 2002; Van der Does and Williams 2003). Further, higher scores on the LEIDS-R prospectively predicted depression onset in healthy individuals 
and a new depressive relapse in depressed individuals(Booij and Van der Does 2007; Kruijt et al. 2013; Figueroa et al. 2015). The LEIDS-R scores also differentiated individuals with severe depression from individuals with milder depression forms (Batmaz et al. 2017,). The rumination and aggression/hostility subscales were helpful for the distinction of depression subtypes, and higher scores on the hopelessness/suicidality and aggression/hostility subscales were reported in depressed individuals with a history of suicide (Moulds et al. 2008; Antypa et al. 2010). Moreover, CR was associated with suicidality independent of anxiety and genetic vulnerability factors for depression (Antypa and Van der Does 2010).

One of the other identified risk factors for suicidal ideation and attempts is rumination (Rogers and Joiner 2017), and it is defined as, "repetitively and passively focusing on symptoms of distress and on the possible causes and consequences of these symptoms" (NolenHoeksema1991). Importantly, this perseverative and fixated thought does not lead to active problem solving (Nolen-Hoeksema et al. 2008). Based on factor analyses conducted by Treynor et al. (2003), rumination is commonly separated into two subtypes: brooding (i.e., 'a passive comparison of one's current situation to some unachieved standard') and reflection (i.e., 'a purposeful turning inward to engage in cognitive problem solving to alleviate one's depressive symptoms'). Rumination and its relationship with suicidal behaviours have been the subject of research in many studies. A systematic review, for example, demonstrated that increased rumination was associated with increased suicidality (Morrison and O'connor 2008). A more recent study reported similar results, in which brooding was specifically associated with suicidal risk, ideation, and attempts regardless of poor sleep (Holdaway et al. 2018). Moreover, Law and Tucker concluded that there was enough evidence to support rumination and other repetitive negative thinking styles as an etiological and maintenance factor of suicidality (Law and Tucker 2018). In another study which was conducted on 352 college students and examined the relation between cognitive styles (i.e. brooding, reflection, distraction) and cognitive 
inflexibility in differentially predicting history of non-suicidal self-injury only, suicide attempt only, or both; the results showed that brooding uniquely predicted suicide attempt only history while reflection uniquely predicted history of non-suicidal self-injury only and both (PolancoRoman et al.2015).

Self-esteem, an individual's sense of his/her value or worth, or the extent to which a person values, approves of, appreciates, prizes, or likes himself/herself (Allen et al. 1991), is another risk factor for suicide (Wild et al. 2004). In a study among college students, even after controlling for the severity of depression, levels of self-esteem were associated with past suicidal ideation (Vella et al. 1996). However, in psychiatric inpatients, the level of self-esteem did not differ between suicidal and non-suicidal adolescents (Dori and Overholser 1999). Yet, other research showed that suicidal behaviours of inpatients were suggestive of lower selfesteem after the attempt (Palmer 2004). Similarly, in psychiatric outpatients, even in the context of depression and hopelessness, low self-esteem was an additional risk factor for suicidal ideation (Bhar et al. 2008). Interestingly, another study reported that damaged self-esteem, defined as high implicit self-esteem combined with low explicit self-esteem, was consistently associated with increased levels of depressive symptoms, suicidal ideation, and loneliness, while defensive or fragile self-esteem, defined as high explicit and low implicit self-esteem, was not (Creemers et al. 2012). Moreover, in another study, low self-esteem in early childhood was linked to suicidal ideation in early adulthood, especially in boys (McGee et al. 2001). Low self-esteem has further been identified as a mediator between gratitude and suicidal ideation (Lin 2015). According to the results of another study which was carried on 62 adolescents, age ranged from 15-18 years, the adolescent group who were hospitalized after a suicide attempt had lower level of self-esteem (Marašet al. 2013). In a similar vein, results of another research revealed that depressed inpatients with a history of suicidal ideation and history of at least one suicide attempt had a significantly higher suicide risk score and significantly lower self-esteem 
score than depressed inpatients with no history of suicidal ideation and no history of suicide attempt as well as a significantly higher risk score and significantly lower self-esteem score than depressed inpatients with a history of suicidal ideation but no history of suicide attempt (Palmer 2004). On the other hand, the literature is equivocal concerning the role of high levels of self-esteem as a protective factor for suicidality (Johnson et al. 2011), and some studies have reported a positive moderating effect of high self-esteem among college students (De Man and Gutierrez 2002; Kleiman and Riskind 2013). Thus, more research is needed to understand the relationship between self-esteem and suicidality.

Personality traits have been investigated as correlates of suicidal behaviours, and neuroticism and extraversion were reported to be related to risk for suicidal ideation, suicide attempts, and completed suicides in a review article (Brezo et al. 2006).Interestingly, a later study demonstrated different results regarding neuroticism, in which a negative correlation was found between neuroticism and suicide rates (Voracek 2009). In another more recent study the results showed that the people who have attempted suicide who suffer from mental disorders present with significantly higher level of neuroticism ( Bi et al. 2017). Consistent with that, in a study in which 365 bipolar, 296 major depressive disorder patients and 315 community controls were recruited to assess their lifetime suicidality, it is revealed that extraversion showed protective effect. High neuroticism or harm avoidance had prominent and independent risk effects on suicidal ideation and attempt ( Su et al. 2018).Further, a large study from Sweden used a factor analysis of a personality questionnaire, and the results indicated that the study population consisting of suicide attempters had no specific personality structure (Hirvikoski and Jokinen 2012). On the other hand, a recent study focusing on the personality factors of patients with depression suggested that the self-directedness character dimension differentiated previous suicide attempters from non-attempters (Seo et al. 2014). This result was replicated in a study population consisting of university students (Lee et al. 2017).Therefore, the literature on the 
effect of personality traits is far from being conclusive, and further research is needed, especially on different age groups.

As summarized above, cognitive style, self-esteem, hopelessness, rumination, cognitive reactivity, and personality characteristics of university students might help to some extent identify who is at risk for suicidal behaviours. Unfortunately, their role in suicide attempts is yet to be determined, and the present findings in the literature are not definitive and some reports are even contradictory. Therefore, the current study aimed to investigate these cognitive factors in university students and to highlight the differences between a group of participants who previously attempted suicide with another group of participants who did not. Further, we aimed to investigate whether the above-mentioned cognitive factors and clinical correlates for suicidal behaviours also played a role in a Turkish college-age population and to demonstrate any potential cultural differences. We also aimed to find out whether any of the correlates were suitable candidates as treatment targets in cognitive behavioural therapy, and subsequently to emphasize the need for early interventions for reduce suicide attempts. We hypothesized that students with a suicide attempt history would score higher on neuroticism, ruminate more frequently, be more prone to depressed mood, feel more hopeless, demonstrate a more negative cognitive style, and have lower self-esteem than students who never attempted suicide. We also hypothesized that a suicide attempt would be associated with higher levels of neuroticism, rumination, cognitive reactivity, hopelessness, negative cognitive style, and lower levels of selfesteem. Further, we hypothesized that these cognitive factors would be correlated with suicide attempts in this Turkish college-age population.

\section{METHODS}

\section{Participants}

A total of 355 young adults aged $18-25$ (mean age (standard deviation, SD) $=19.59(6.27)$ years, $72.7 \%$ female, $97.2 \%$ single) were recruited for this study. The participants were Turkish 
university freshmen who were taking a developmental psychology, behavioural science or nursing course, and they were offered extra credit if they participated in the study. Participants who had any psychiatric disorders which might prevent answering the questions of the scales (e.g. who were in an acute psychotic/manic episode), or who had serious suicidal ideation or presented with a suicide attempt at the time of the interview were excluded from the study.

For statistical analyses, the participants were classified into two groups, i.e. participants who previously attempted suicide and participants who never did. Thirty-four of the 355 young adults $(9.58 \%)$ had attempted suicide previously. The groups differed from each other in terms of their marital status, family history of psychiatric disorder, and previous treatment for a psychiatric disorder. Participants with a suicide attempt history were less likely to be married, more frequently had a family member with a psychiatric disorder, and had received treatment for psychiatric disorder more frequently. These results are presented in Table 1.

\section{Table 1 to be placed around here}

\section{Procedure}

The students were briefed about the study aims and if they agreed to take part in the study, they were invited to the outpatient clinic of the psychiatry department for a clinical interview. The interviews were scheduled on different time points, so the students did not come across each other during the interviews.A face-to-face semi-structured diagnostic interview was conducted by experienced psychiatrists or psychiatry residents according to the criteria of the Diagnostic and Statistical Manual of Mental Disorders, Fifth Edition (American Psychiatric Association, 2013). The semi-structured interview was based on the Mini International Neuropsychiatric Interview, and the module on suicidality was completed to assess for previous suicide attempts ( Sheehan et al. 1998). After the diagnostic interview, participants were asked to complete the clinical measures used in the study. All the measures that were used in this study were self- 
report scales, and it took the participants about 30-45 minutes to complete all of them. Turkish versions of the scales were used in the study.

\section{Clinical Measures}

Demographic and Clinical Data Form: This form was developed by the investigators, and it consisted of questions about the age, sex, marital status, family history of psychiatric disorder, previous psychiatric treatment history, comorbid medical disorder, and whether the participant ever attempted suicide.

Hospital Anxiety and Depression Scale (HADS) (Zigmond and Snaith 1983): This is a 14-item self-report scale, which is used to screen for, and to determine the severity of depressive and anxiety-related symptoms. The Turkish version has a cut-off score of 7 for depression, and 10 for anxiety (Aydemir et al. 1997).

Ten-Item Personality Inventory (TIPI) (Gosling et al. 2003): This is a brief measure based on the five-factor model of personality, and it consists of five dimensions, i.e. openness to experience, extraversion, agreeableness, emotional stability, and conscientiousness. The TIPI was reported to correlate well with much lengthier scales that measure the same personality dimensions. The Turkish version of the scale was used in this study (Atak 2013).

Ruminative Response Scale-Short Form (RRS) (Treynor et al. 2003): This scale is used to rate the severity of rumination, which has previously been reported to correlate with depression. The scale has two subscales, i.e. reflection, and brooding. While the reflection subscale is considered to help individuals cope with negative affect by facilitating problem-solving, the brooding subscale is generally considered not to be an adaptive way of overcoming problems or distressing thoughts. A total score of the RRS might also be used to measure the intensity of rumination, and the higher the score, the more engagement in rumination. In the present study, the Turkish version of the RRS (Erdur-Baker and Bugay 2010) was used with a Cronbach's $\alpha$ of 0.772 . 
Leiden Index of Depression Sensitivity-Revised (LEIDS-R) (Van der Does 2002): This is a 34item self-report scale, consisting of six subscales, and higher scores on this scale demonstrate higher degrees of cognitive reactivity (CR) to depression. The subscales of the scale are hopelessness/suicidality (HOP), acceptance/coping (COP), aggression/hostility (AGG), control/perfectionism (CON), risk aversion (RAV), and rumination (RUM). All of these subscales have been defined as psychological vulnerability factors to depression. The Turkish version of the LEIDS-R was used in this study (Batmaz et al. 2015), and its Cronbach's $\alpha$ was 0.878 .

Beck Hopelessness Scale (BHS) (Beck et al. 1974): This is a 20-item self-report inventory, and it is used to measure the three aspects of hopelessness, i.e. feelings about the future, loss of motivation, and expectations. The BHS may be used to identify the risk of suicide patients with depression who previously attempted suicide. The higher the scores, the higher the risk for suicide. The Turkish version of the BHS was used (Durak and Palabiyikoglu 2006), and it had a Cronbach's $\alpha$ value of 0.852 .

Cognitive Style Questionnaire-Short Form (CSQ) (Meins et al. 2012): This is a self-report scale consisting of 72 statements about 8 hypothetical negative situations, and it is used to assess the negative cognitive style of the respondents, which may be associated with vulnerability to depression. The CSQ is based on the hopelessness theory of depression, and it consists of 5 dimensions, i.e. internality, globality, stability, self-worth, and negative consequences. These dimensions propose that a person with a negative cognitive style makes negatively biased inferences about the causes, consequences, and self-worth implications of negative life events. Higher scores on these dimensions indicate a more negative view of the self, the life event itself, and the future. The Turkish version of the CSQ was used in this study (Batmaz et al. 2015), and the Cronbach's $\alpha$ was 0.853 . 
Rosenberg Self-Esteem Scale (RSES) (Rosenberg 1965): This is a 10-item self-report scale, and it is used to assess self-esteem. Higher scores on the RSES correspond to lower levels of self-esteem. The Turkish version of the RSES was used in this study (Cuhadaroglu 1985).

\section{Statistical Analyses}

All analyses were performed using SPSS for Windows, Version 22.0 (IBM Corp 2013). Demographic and clinical data of the participants were analyzed by descriptive statistics. For group comparisons, independent samples $t$-test and chi-squared were used. Bonferroni corrections were applied when there were multiple comparisons. Intercorrelations between suicide attempt and other variables were evaluated by Pearson's correlation coefficients. A binary logistic regression model with stepwise backward selection method was used to identify the correlates for a suicide attempt, in which the dependent variable was the presence of a suicide attempt, and the correlates were age, sex, personality characteristics, and the total scores of the scales used in the study. Statistical significance was set at a $p$-value $<0.05$.

\section{Ethical approval}

The study was carried out at the outpatient psychiatric clinic of Tokat Gaziosmanpasa University Hospital (Tokat, Turkey). Before conducting this study, ethical committee approval was obtained from the Clinical Research Ethics Committee, and all participants gave written informed consent.

\section{RESULTS}

A total of 355 university students, of whom 34 were previous suicide attempters, were recruited for this study. Demographic features and group statistics are presented in Table 1. There were no differences between the groups in terms of age and gender. $88.2 \%$ of previous suicide attempters were single, $35.3 \%$ had a positive family history, and $33.3 \%$ had previous psychiatric treatment history $(\mathrm{p}=0.001, \mathrm{p}<0.001, \mathrm{p}<0.001$, respectively). Social support and quality of life 
mean scores were higher in the group who had no previous suicide attempts $(\mathrm{p}<0.001$, and $\mathrm{p}=0.003$, respectively). There were no statistically significant differences between the HADSAnx and HADS-Dep mean scores of the groups. Among the ruminative response subscale scores, RRS-BROOD was higher in attempters group $(\mathrm{p}=0.008)$. LEIDS-R scale mean score was $63.70( \pm 16.95)$ in the attempters group, but not statistically significantly different $(\mathrm{p}=0.460)$ whereas the BHS mean score was $7.94( \pm 5.63)$ and the difference was statistically significant $(\mathrm{p}=0.005)$ compared to the non-attempters. TIPI-A mean score was higher in the non-attempters group ( $\mathrm{p}=0.009$ ). CSQ total score, CSQ-Stab, and CSQ-Glob scores were also higher in the previous suicide attempters group $(\mathrm{p}<0.001)$.

Table 2 presents the correlations between the study variables. RRS, BHS, CSQ-SF mean scores were higher in the suicide attempter group and also statistically correlated with a suicide attempt $(\mathrm{p}<0.5, \mathrm{p}<0.01, \mathrm{p}<0.01$ respectively).

Table 2 to be placed around here

Table 3 shows the results of the logistic regression analysis, and correlates of suicide attempt. Higher scores of RRS (OR=1.077), BHS (OR=1.109), and CSQ (OR=1.023) were significant factors associated with a suicide attempt. This association revealed that the cognitive style, hopelessness and rumination may be correlated withsuicide attempts. Lower scores of TIPI-A (OR=0.602), and RSES (OR=0.499) were also significant correlates of previous suicide attempts. TIPI-C scores were not significantly associated with suicide attempt.

Table 3 to be placed around here

\section{DISCUSSION}

Since suicide is one of the major public health problems, detecting its risk factors and predictors in order to prevent it, and find therapeutic ways to handle it have become essential issues in the field of psychiatry. In this study, we investigated the differences between the cognitive profile of university students who attempted to commit suicide and who did not. In our study, the term 
'cognitive profile of the students' was referred to combination of repetitive negative thinking, negative attributional style, cognitive reactivity, hopelessness, and self-esteem. Cognitive reactivity to depression, cognitive style, rumination, hopelessness, personality traits, and selfesteem were each evaluated with self-report scales. Higher RRS, BHS, CSQ-SF scores were significantly associated with suicide attempt in the logistic regression analysis, and this association revealed that negative cognitive style, hopelessness and rumination may have correlation with suicide attempts. Lower TIPI-A and RSES scores were also significant correlates in this model, and the results revealed that agreeableness in personality trait and high self-esteem were negatively correlated withsuicide attempts. Overall, significant differences in the cognitive style, cognitive reactivity, and personality traits between the groups might highlight correlates for suicide attempts, and guide clinicians to proper therapeutic approaches. Therefore, the current study's findings partially confirmed our hypotheses.

\section{Hopelessness and Suicide Attempt}

In this current study, one of our research hypothesis was that hopelessness has an important role in the aetiology of depression and could be a correlate for suicidality. In several previous studies this issue was repeatedly investigated (Chioqueta and Stiles 2005; Elis et al. 2016; Klonsky et al. 2012; Links et al. 2012). In our cross-sectional study, group comparisons of BHS mean scores were higher in the attempters, and this was statistically significant. Besides this finding, our logistic regression analysis revealed that BHS was a significant factor associated with a suicide attempt. Previously, a prospectively designed 10-year follow-up study suggested that hopelessness reliably predicted attempted suicide up to 4 to 6 years later, but not beyond and that it could be accepted as one of the important predictors of suicide attempt (Klonsky et al. 2012). In another prospective cohort study, which was designed by Links et al. (2012) patients were followed-up 1, 3 and 6 months after hospital discharge. One of the significant results of this trial was that higher suicide ideation at 1 month following discharge was 
significantly related to the level of hopelessness reported by the participant during hospital admission. Thus, it was suggested that hopelessness could be a predictor for suicide ideation and attempt (Links et al. 2012). Overall, our findings were consistent with these previous results.

\section{Cognitive Style and Suicide Attempt}

The role of negative cognitive style in depression, and also in the development of suicidal ideation has been supported by research (Alloy et al. 2006; Kleiman et al. 2014). In this model, individuals who are vulnerable to depression and suicide are said to have a negative cognitive style in which they attribute stable and global causes to the occurrence of negative events, and expect negative future implications from the events. Indeed, several studies found that negative cognitive style interacted with (i.e., was activated by) negative events to predict suicidal ideation (Hirsch et al. 2009; Joiner and Rudd 1995; Priester and Clum1992; Stange et al. 2015). In the present study, consistent with our hypotheses, CSQ total scores, globality and stability scores, which may be used as an indicator of negative cognitive style, were higher in the attempters group. Besides these results, CSQ total scores were significantly associated with suicide attempt in the logistic regression analysis, which may suggest that there was a relationship between negative cognitive style and suicidal attempt.

\section{Rumination and Suicide Attempt}

Rumination has two subtypes: brooding and reflection. In several trials, there were reports that brooding and/or reflection might be associated with suicide attempt (Chan et al. 2009; Stage et al. 2015;). In our study, brooding mean scores were higher in the attempters group, and this result was statistically significant. Reflection mean scores and RRS total scores were also higher in the previous suicide attempters group, but they were not statistically significant. In many previous clinical trials, it was indicated that brooding was more strongly associated with 
suicidal ideation than reflection (Treynor et al. 2003;Miranda and Nolen-Hoeksema 2007;O'Connor and Noyce2008), and our findings were compatible with these previous results. However, in a study, which was designed by Stange et al. (2015) the results were only significant for reflection, but not for brooding, and they suggested that reflection might lead to suicidal ideation among individuals with certain vulnerabilities. In the correlation analysis of our study, RRS mean scores correlated with a suicide attempt. In the logistic regression analysis, RRS scores were significant correlates for a suicide attempt. Overall, considering these results, we may suggest thatthere was a relationship between rumination and suicidal attempt.

\section{Cognitive Reactivity and Suicide Attempt}

Cognitive reactivity to depression is another notable issue in suicide ideation and attempt. In our study, LEIDS-R total scores were higher in the attempters group, but this was not statistically significant. HADS-Dep mean scores were also not significantly different between the groups. This may be the reason why the LEIDS-R total scores remained similar between the groups. In addition, HOP and AGG subscales, which were reported to be elevated in depressed individuals with a history of suicide, were not statistically different between the groups. In the logistic regression analysis, LEIDS-R and its subscales were not found to be associated with suicide attempts. However, in a previous study, which was carried out by Antypa et al., the results supported that LEIDS-R total score and LEIDS-HOP subscale score could be a predictor of prior suicidality (Antypa et al. 2010). The current study failed to replicate these findings.

\section{Self-esteem, Personality Traits, and Suicide Attempt}

Self-esteem and personality traits are other important issues for suicide ideation and attempt. Low self-esteem has been implicated in samples of adolescents who have attempted suicide (Kienhorst et al. 1990), and it has also been found to be related to increased suicidal tendencies, 
and seriousness of suicidal intent in adolescent psychiatric inpatients (Robbins and Alessi 1985). In a previous study, which was carried out by Brausch and Gutierrez, it was suggested that low self-esteem could be a risk factor for non-suicidal self-injury, and also for suicide attempt (Brausch and Gutierrez 2010). Our findings, consistent with previous studies, demonstrated that low self-esteem was correlated with suicide attempt. The most popular model of personality in recent decades has been the Five Factor Model. Some of the studies based on this personality model suggested that emotional instability was related to suicidal ideation (Chioqueta and Stiles 2005; DeShongrt al. 2015; Kerby 2003; Velting 1999). Findings of the relevance of other personality traits showed a relationship between suicidal ideation and low Extraversion (DeShong et al. 2015), a relationship with low Conscientiousness (Kerby 2003; Velting 1999), low Agreeableness (Kerby 2003), and high Openness to experience (Chioqueta and Stiles 2005). In our study, only the Agreeableness was negatively correlated with suicide attempt. Other traits were not correlated with a suicide attempt.

Future implications

The current findings of our study enhance our understanding of the risks and correlates of suicide attempts among university students. Determining the risk factors for suicide has an important role in both preventing suicide and choosing the right treatment modality. During the clinical intervention of a patient, the crucial findings of the cognitive profile of the patient can guide us. Systematically assessing the cognitive style, cognitive reactivity, personal traits etc. of the patient can enhance understanding of potential mechanisms of the suicide ideation or attempt, and choosing the appropriate therapeutic approaches such as cognitive behavioural approaches.

This study has some important clinical implications. First, since this was a cross-sectional study with suicide attempts having happened in the past, the current cognitive profile of the university students might actually be clues for trait-like characteristics of their cognitive profile rather than 
being due to emotional state-dependent changes. Accordingly, targeting rumination, negative cognitive style, and hopelessness, and fostering self-esteem even when students are not experiencing psychiatric difficulties may have protective qualities against suicide attempts. Second, group differences between suicide attempters and non-attempters provide insight into which items should be directly added to the agenda of a therapeutic intervention after a suicide attempt and alleviating hopelessness, negative cognitive style, and rumination, as well as increasing self-esteem, might prove helpful in offering psychotherapy. Third, the high rate of suicide attempts in Turkish university students warrants the need for education about vulnerability to suicide and screening for mental health issues in youth. Early identification of individuals under risk might decrease the number of suicide-related losses, and increase awareness about psychiatric disorders. Fourth, a study like this, in which a comprehensive assessment of different psychological models of suicide was used, might help better understand and conceptualize cases with a previous suicide attempt, and facilitate an integrative individualized therapeutic approach to each case. Fifth, given the significant relationship of cognitive processes involved in suicide attempts, these results indicate that cognitive behavioural therapy and its variations like metacognitive therapy for rumination need to be further implemented for the treatment of suicide survivors. There is still a great lack of evidence-based treatment options for survivors of suicide and studies in which the cognitive processes proposed in the current study may be selectively offered to people who attempted to commit suicide to better identify the core components of therapy needed to be targeted to achieve optimal results in preventing newer attempts.

\section{Strength and Limitations}

Several strengths and limitations of the study need to be mentioned. In the current study, our data consisted of a large sample size. Additionally, our study was carried on a community sample of university students, which may limit the occurrence of confounding factors that result 
from comorbid psychopathologies when clinical samples are used. Because of the complexity of the suicidal process, using a multivariate approach in this study was another strength of this study. This is also one of the few studies focusing specifically on suicidality in Turkish university students, and a wide range of psychological instruments of assessment was used, which helped investigate a relatively comprehensive picture of the cognitive profile of these students. Yet, the present study has also some limitations. First, in this study, self-report measures were used. As known, self-report instruments are subject to social desirability, which can push responders to deny certain problems. Second, our study was cross-sectional, and a history of suicidal attempt was documented only respectively and relied solely on the report of the participants. Third, due to the cross-sectional design of the study, it is not clear whether the current findings were as a result of the scarring caused by a suicide attempt or whether this specific cognitive profile represented vulnerability for suicide attempts. It is unquestionable that a prospective study may be needed to confirm the causal relationship between the cognitive profile and future suicide ideation and attempt. Fourth, although the religion may have an important role on suicide, we did not collect any data on religious faith or spirituality for the study, so we can not comment on any relationship between these variables and suicide attempt.

\section{Conclusion}

In conclusion, the findings of this study indicated that hopelessness, negative cognitive style, rumination (brooding), and cognitive reactivity to depression had some impact on suicide attempts in Turkish university students. Among these factors, cognitive style, hopelessness, and rumination were strong and significant correlates of suicide attempts. Furthermore, high selfesteem and agreeableness were found negatively correlated with suicide attempt, and this was yet another remarkable finding of this study. Increasing our understanding of the risk factors and correlates of suicide is an important step toward enhancing suicide prevention among university students, and also toward providing proper treatment with better outcomes. 


\section{COMPLIANCE WITH ETHICAL STANDARDS}

All procedures performed in studies involving human participants were in accordance with the ethical standards of the institutional and/or national research committee and with the 1964 Helsinki Declaration and its later amendments or comparable ethical standards. Informed consent was obtained from all individual participants involved in the study.

\section{CONFLICT OF INTEREST}

The authors declare that they have no conflicts of interest.

\section{TABLE HEADINGS}

Table 1. Demographic features and group differences for scale scores between groups that did or did not attempt suicide

Table 2. Intercorrelations for suicide attempt and correlates

Table 3. Last step of the logistic regression analysis and correlates of suicide attempt

\section{REFERENCES}

Abramson, L. Y., Alloy, L. B., Hogan, M. E., Whitehouse, W. G., Gibb, B. E., Hankin, B. L. et al. (2002). The hopelessness theory of suicidality. Suicide science (pp. 17-32). Springer, Boston, MA.

Allen, K. M., Blascovich, J., Tomaka, J., \& Kelsey, R. M. (1991). Presence of human friends and pet dogs as moderators of autonomic responses to stress in women. Journal of Personality and Social Psychology, 61(4), 582589.

Alloy, L.B., Abramson, L. Y., Whitehouse, W. G., Hogan, M. E., Panzarella, C., \& Rose, D. T. (2006). Prospective incidence of first onsets and recurrences of depression in individuals at high and low cognitive risk for depression. Journal of Abnormal Psychology. 115(1), 145-156.

Aloba, O., Akinsulore, A., Mapayi, B., Oloniniyi, I., Mosaku, K., Alimi, T., \& Esan, O. (2015). The Yoruba version of the Beck Hopelessness Scale: Psychometric characteristics and correlates of hopelessness in a sample of Nigerian psychiatric outpatients. Comprehensive Psychiatry, 56, 258-271.

American Foundation for Suicide Prevention. [(accessed on 15 October 2017)]. https://afsp.org/about$\underline{\text { suicide/suicide-statistics/ }}$

American Psychiatric Association. (2013). DSM-V. APA.

Antypa, N., \& Van der Does, A. J. W. (2010). Serotonin transporter gene, childhood emotional abuse and cognitive vulnerability to depression. Genes, Brain and Behavior, 9, 615-620.

Antypa, N., Van der Does, A. W., \& Penninx, B. W. (2010). Cognitive reactivity: investigation of a potentially treatable marker of suicide risk in depression. Journal of affective disorders, 122(1-2), 46-52.

Assari, S. (2018). Multiplicative Effects of Social and Psychological Risk Factors on College Students' Suicidal Behaviors. Brain Sciences 8(5), pii: E91. https://doi.org/ 10.3390/brainsci8050091.

Atak, H. (2013). The Turkish adaptation of the ten-item personality inventory. Archives of Neuropsychiatry, 50(4), 312.

Auerbach, R. P., Alonso, J., Axinn, W. G., Cuijpers, P., Ebert, D. D., Green, J. G., et al. (2016). Mental disorders among college students in the WHO World Mental Health Surveys. Psychological Medicine, 46(14), 2955-2970. Aydemir, O., Guvenir, T., Kuey, L., \& Kultur, S. (1997). Validity and reliability of Turkish version of Hospital Anxiety and Depression Scale. Turkish Journal of Psychiatry, 8(4), 280-287.

Bachmann, S. (2018). Epidemiology of Suicide and the Psychiatric Perspective. International Journal of Environmental Research and Public Health, 15(7), 1425. 
Bakhiyi, C. L., Calati, R., Guillaume, S., \& Courtet, P. (2016). Do reasons for living protect against suicidal thoughts and behaviors? A systematic review of the literature. Journal of Psychiatric Research, 77, 92-108.

Batmaz, S., Kocbiyik, S., \& Yuncu, O. A. (2015). The reliability and validity of the Turkish version of the Leiden Index of Depression Sensitivity: Preliminary results. Turkish Journal of Psychiatry, 26(1), 4.

Batmaz, S., Kocbiyik, S., \& Yuncu, O. A. (2017). Cognitive Reactivity in Depressed Outpatients: How Different is Severe Depression?.Journal of Rational-Emotive \& Cognitive-Behavior Therapy, 35(2), 173-186.

Batmaz, S., Oguz, G., Turhan, L., Yuncu, O. A., Kocbiyik, S., Sezgin, S., et al. (2015). The Reliability and Validity Study of Turkish Version of Short Form of The Cognitive Style Questionnaire in University Student Sample: Preliminary Results. Paper presented at the 4th National Congress of the Cognitive and Behavior Therapies, Istanbul, Turkey.

Beck, A. T., Weissman, A., Lester, D., \& Trexler, L. (1974). The measurement of pessimism: the Hopelessness Scale. Journal of Consulting and Clinical Psychology. 42, 861-65.

Beck, A., Brown, G., Berchick, R. J., Stewart, B. L., \& Steer, R. A. (1990). Relationship between hopelessness and ultimate suicide: A replication with psychiatric outpatients. American Journal of Psychiatry, 147(2), 190-195. Beck, A., Steer, R. A., Kovacs, M., \& Garrison, B. (1985). Hopelessness and eventual suicide: A 10-year prospective study of patients hospitalized with suicidal ideation. American Journal of Psychiatry, 142(5), 559563.

Becker, S.P., Holdaway, A. S., \& Luebbe, A. M. (2018). Suicidal Behaviors in College Students: Frequency, Sex Differences, and Mental Health Correlates Including Sluggish Cognitive Tempo. Journal ofAdolescentHealth ,63(2), 181-188.

Bertolote, J. M., Fleischmann, A., De Leo, D., \& Wasserman, D. (2003). Suicide and mental disorders: Do we know enough? The British Journal of Psychiatry, 183, 382-383.

Bertolote, J. M., Fleischmann, A., De Leo, D., Phillips, M. R., Botega, N. J., Vijayakumar, L., et al. (2010). Repetition of suicide attempts: Data from emergency care settings in five culturally different low- and middleincome countries participating in the WHO SUPRE-MISS Study. Crisis, 31(4), 194-201.

Bertolote, J.M., Fleischmann, A., De Leo, D., Bolhari, J., Botega, N., De Silva, D., et al. (2005). Suicide attempts, plans, and ideation in culturally diverse sites: The WHO SUPRE-MISS community survey. Psychological Medicine, 35(10), 1457-1465.

Bhar, S., Ghahramanlou-Holloway, M., Brown, G., \& Beck, A. T. (2008). Self-esteem and suicide ideation in psychiatric outpatients. Suicide and Life-Threatening Behavior, 38(5), 511-516.

Bi, B., Liu, W., Zhou, D., Fu, X., Qin, X., \& Wu, J. (2017). Personality traits and suicide attempts with and without psychiatric disorders: analysis of impulsivity and neuroticism. BMC Psychiatry, 17(1), 294.

Booij, L., \& van der Does, A. J. W. (2007). Cognitive and serotonergic vulnerability to depression: Convergent findings. Journal of Abnormal Psychology, 116, 86-94.

Borschmann, R., Stark, P., Prakash, C., \& Sawyer, S. M. (2018). Risk profile of young people admitted to hospital for suicidal behaviour in Melbourne, Australia. Journal of Paediatrics and Child Health. https://doi.org/10.1111/jpc.13938.

Brausch, A. M., \& Gutierrez, P. M. (2010). Differences in non-suicidal self-injury and suicide attempts in adolescents. Journal of Youth and Adolescence, 39(3), 233-42.

Brezo, J., Paris, J., \& Turecki, G. (2006). Personality traits as correlates of suicidal ideation, suicide attempts, and suicide completions: a systematic review. Acta Psychiatrica Scandinavica, 113(3), 180-206.

Butter, S., Shevlin, M., \& Murphy, J. (2019). Negative self-evaluation and the genesis of internal threat: beyond a continuum of suicidal thought and behaviour. Psychological Medicine, 49(15), 2591-2599.

Centers for Disease Control and Prevention Suicide. [(accessed on 21 November 2017)]. http://www.cdc.gov/ViolencePrevention/pdf/Suicide_DataSheet-a.pdf.

Chan, S., Miranda, R., \& Surrence, K. (2009). Subtypes of rumination in the relationship between negative life events and suicidal ideation. Archives of Suicide Research, 13(2), 123-135.

Chioqueta, A. P., \& Stiles, T. C. (2003). Suicide risk in outpatients with specific mood and anxiety disorders.Crisis the Journal of Crisis Intervention and Suicide Prevention, 24, 105-112.

Chioqueta, A. P., \& Stiles, T. C. (2005). Personality traits and the development of depression, hopelessness, and suicide ideation. Personality and Individual Differences, 38(6), 1283-1291.

Coskun, M., Zoroglu, S., \& Ghaziuddin, N. (2012). Suicide rates among Turkish and American youth: a crosscultural comparison. Archives of suicide research, 16(1), 59-72.

Creemers, D. H., Scholte, R. H., Engels, R. C., Prinstein, M. J., \& Wiers, R. W. (2012). Implicit and explicit selfesteem as concurrent predictors of suicidal ideation, depressive symptoms, and loneliness. Journal of behavior therapy and experimental psychiatry, 43(1), 638-646.

Crosby, A., Ortega, L., \& Melanson, C. (2011). Self-directed violence surveillance; uniform definitions and recommended data elements. Atlanta, GA: Centers for Disease Control and Prevention, National Center for Injury Prevention and Control. 
Cuhadaroglu, F. (1985). Self-esteem in adolescents. (Unpublished Master's Degree Dissertation). Hacettepe University Faculty of Medicine, Ankara, Turkey.

David Klonsky, E., Kotov, R., Bakst, S., Rabinowitz, J., \& Bromet, E. J. (2012). Hopelessness as a predictor of attempted suicide among first admission patients with psychosis: a 10-year cohort study. Suicide and Life Threatening Behavior, 42(1), 1-10.

De Leo, D., Cerin, E., Spathonis, K., \& Burgis, S. (2005). Lifetime risk of suicide ideation and attempts in an Australian community: prevalence, suicidal process, and help-seeking behaviour. Journal of Affective Disorders, 86, 215-224.

De Man, A. F., \& Gutierrez, B. I. (2002). The relationship between level of self-esteem and suicidal ideation with stability of self-esteem as moderator. Canadian Journal of Behavioural Science/Revue canadienne des sciences du comportement, 34(4), 235.

DeShong, H. L., Tucker, R. P., O’Keefe, V. M., Mullins Sweatt, S. N., \& Wingate, L. R. (2015). Five factor model traits as a predictor of suicide ideation and interpersonal suicide risk in a college sample. Psychiatry Research, 226(1), 217-223.

Dori, G. A., \& Overholser, J. C. (1999). Depression, hopelessness, and self-esteem: Accounting for suicidality in adolescent psychiatric inpatients. Suicide and Life-Threatening Behavior, 29(4), 309-318.

Drum, D. J., Brownson, C., Denmark, A. B., \& Smith, S. E. (2009). New Data on the Nature of Suicidal Crises in College Students: Shifting the Paradigm. Professional Psychology-Research and Practice, 40(3), 213-222.

Durak, A., \& Palabiyikoglu, R. (2006). The reliability and validity of the Turkish version of the Beck Hopelessness Scale. KrizDergisi, 2(2), 311-319.

Efstathiou, V., Papadopoulou, A., Christodoulou, C., Gournellis, R.,Michopoulos, I. Ferentinos, P., et al. (2018) The Relationship between Hopelessness and Clinical Characteristics of Hospitalized Patients with Recent Suicide Attempt, Issues in Mental Health Nursing, 39(10), 876-882.

Ellis, T. E., Rufino, K. A., \& Green, K. L. (2016). Implicit Measure of Life/Death Orientation Predicts Response of Suicidal Ideation to Treatment in Psychiatric Inpatients. Archives of Suicide Research, 20(1), 59-68.

Erdur-Baker, Ö., \& Bugay, A. (2010). The short version of ruminative response scale: reliability, validity and its relation to psychological symptoms. Procedia-Social and Behavioral Sciences, 5, 2178-2181.

Figueroa, C. A., Ruhé, H. G., Koeter, M. W., Spinhoven, P., Van der Does, W., Bockting, C. L., et al. (2015). Cognitive reactivity versus dysfunctional cognitions and the prediction of relapse in recurrent major depressive disorder. The Journal of Clinical Psychiatry, 76(10), 1306-1312.

Franklin, J. C., Ribeiro, J. D, Fox, K. R., Bentley, K. H., Kleiman, E. M., Huang, X., et al.(2017). Risk factors for suicidal thoughts and behaviors: A meta-analysis of 50 years of research. Psychological Bulletin, 143(2), 187-232. Gosling, S. D., Rentfrow, P. J., \& Swann, W. B., Jr. (2003). A Very Brief Measure of the Big Five Personality Domains. Journal of Research in Personality, 37, 504-528.

Grassia, M., \& Gibb, B. E. (2009). Rumination and lifetime history of suicide attempts. International Journal of Cognitive Therapy, 2(4), 400-406.

Hewitt, P., Norton, G., Flett, G.L., Callander, L., \& Cowan, T. (1998). Dimensions of perfectionism, hopelessness, and attempted suicide in a sample of alcoholics. Suicide and life-threatening behavior, 28, 395-406.

Hirsch, J. K., Wolford, K., LaLonde, S. M., Brunk, L., \& Parker-Morris, 2009. A. Optimistic explanatory style as a moderator of the association between negative life events and suicide ideation. Crisis, 30(1), 48-53.

Hirvikoski, T., \& Jokinen, J. (2012). Personality traits in attempted and completed suicide. European Psychiatry, 27(7), 536-541.

Holdaway, A. S., Luebbe, A. M., \& Becker, S. P. (2018). Rumination in relation to suicide risk, ideation, and attempts: Exacerbation by poor sleep quality?.Journal of affective disorders, 236, 6-13.

Jacobs, R. H,, Reinecke, M. A,,Gollan, J. K., \& Kane, P. (2008). Empirical evidence of cognitive vulnerability for depression among children and adolescents: a cognitive science and developmental perspective. Clinical Psychology Review, 28(5), 759-82.

Jaiswal, S. V., Faye, A. D., Gore, S. P., Shah, H. R., \& Kamath, R. M. (2016). Stressful life events, hopelessness, and suicidal intent in patients admitted with attempted suicide in a tertiary care general hospital. Journal of Postgraduate Medicine, 62(2), 102-104.

Johnson, J., Wood, A. M., Gooding, P., Taylor, P. J., \& Tarrier, N. (2011). Resilience to suicidality: The buffering hypothesis. Clinical psychology review, 31(4), 563-591.

Joiner, T. E. Jr, \& Rudd, M. D. (1995). Negative attributional style for interpersonal events and the occurrence of severe interpersonal disruptions as predictors of self-reported suicidal ideation. Suicide and Life-Threatening Behavior, 25 (2), 297-304.

Kerby, D. S. (2003). CART analysis with unit-weighted regression to predict suicidal ideation from Big Five traits. Personality and Individual Differences, 35(2), 249-261.

Kienhorst, C. W. M., de Wilde, E. J., Diekstra, R. F. W., \& Wolters, W. H. G. (1992). Differences between adolescent suicide attempters and depressed adolescents ActaPsychiatrica Scandinavica, 85, 222-228. 
Kienhorst, W., De Wilde, E., Van Den Bout, J., Diekstra, R., \& Wolters, W. (1990). Characteristics of suicide attempters in a population-based sample of Dutch adolescents. British Journal of Psychiatry, 156, $243-248$.

Kleiman, E. M., \& Riskind, J. H. (2013). Utilized social support and self-esteem mediate the relationship between perceived social support and suicide ideation: A test of a multiple mediator model. Crisis: The Journal of Crisis Intervention and Suicide Prevention, 34(1), 42.

Kleiman, E. M., Law, K. C., \& Anestis, M. D. (2014). Do theories of suicide play well together? Integrating components of the hopelessness and interpersonal psychological theories of suicide. Comprehensive Psychiatry, 55(3), 431-438.

Kleiman, E. M., Riskind, J. H., Stange, J. P., Hamilton, J. L., \& Alloy, L. B. (2014). Cognitive and interpersonal vulnerability to suicidal ideation: A weakest-link approach. Behavior Therapy, 45(6), 778-790.

Klonsky, E. D., Kotov, R., Bakst, S., Rabinowitz, J. \& Bromet, E. J. (2012). Hopelessness as a predictor of attempted suicide among first admission patients with psychosis: A 10-year cohort study. Suicide and LifeThreatening Behavior, 42(1), 1-10.

Kruijt, A. W., Antypa, N., Booij, L., de Jong, P. J., Glashouwer, K., Penninx, B. W. J. H., et al. (2013). Cognitive reactivity, implicit associations, and the incidence of depression: A two-year prospective study. http://doi.org/10.1371/journal.pone.0070245.

Law, K. C., \& Tucker, R. P. (2018). Repetitive negative thinking and suicide: a burgeoning literature with need for further exploration. Current opinion in psychology, 22, 68-72.

Lee, K., Lee, H. K., \& Kim, S. H. (2017). Temperament and character profile of college students who have suicidal ideas or have attempted suicide. Journal of affective disorders, 221, 198-204.

Leverich, G.S., Altshuler, L.L., Frye, M.A., Suppes, T., Keck, P.E., Jr, McElroy, S.L, et al. (2003). Factors associated with suicide attempts in 648 patients with bipolar disorder in the Stanley Foundation Bipolar Network. Journal of Clinical Psychiatry, 64(5), 506-515.

Lin, C. C. (2015). The relationships among gratitude, self-esteem, depression, and suicidal ideation among undergraduate students. Scandinavian journal of psychology, 56(6), 700-707.

Links, P., Nisenbaum, R., Ambreen, M., Balderson, K., Bergmans, Y., Eynan, R., et al. (2012). Prospective study of risk factors for increased suicide ideation and behavior following recent discharge. General Hospital Psychiatry, 34(1), 88-97.

Malhi, G. S., Bargh, D.M., Kuiper, S., Coulston, C. M., \& Das P. (2013). Modelingbipolar disorder suicidality.Bipolar Disorder, 5(5), 559-574.

Maraš, J. S., Kolundžija, K., Dukić, O., Marković, J., Okanović, P., Stokin, B., et al. (2013). Some psychological characteristics of adolescents hospitalized following a suicide attempt. European Review for Medical and Pharmacological Sciences, 17 (1), 50-54.

Mccullumsmith, C. B., Williamson, D. J., May, R. S., Bruer, E. H., Sheehan, D. V., \& Alphs, L. D. (2014).Simple Measures of Hopelessness and Impulsivity are Associated with Acute Suicidal Ideation and Attempts in Patients in Psychiatric Crisis. Innovations in Clinical Neuroscience, 11(9-10), 47-53.

McGee, R., Williams, S., \& Nada-Raja, S. (2001). Low self-esteem and hopelessness in childhood and suicidal ideation in early adulthood. Journal of abnormal child psychology, 29(4), 281-291.

Meins, E., McCarthy-Jones, S., Fernyhough, C., Lewis, G., Bentall, R. P., \& Alloy, L. B. (2012). Assessing negative cognitive style: Development and validation of a Short-Form version of the Cognitive Style Questionnaire. Personality and individual differences, 52(5), 581-585.

Melges, F. T., \& Bowlby, J. (1969). Types of hopelessness in psychopathological process. Archives and General Psychiatry, 20(6), 690-9.

Miranda, R., \& Nolen-Hoeksema, S. (2007). Brooding and reflection: rumination predicts suicidal ideation at 1year follow-up in a community sample. Behaviour Research and Therapy, 45(12), 3088-3095.

Morrison, R., \& O'connor, R. C. (2008). A systematic review of the relationship between rumination and suicidality. Suicide and Life-Threatening Behavior, 38(5), 523-538.

Mortier, P., Auerbach, R. P., Alonso, J., Axinn, W. G., Cuijpers, P., Ebert, D. D.,et al. (2018b). Suicidal thoughts and behaviors among college students and same-aged peers: results from the World Health Organization World Mental Health Surveys. Social psychiatry and psychiatric epidemiology, 53(3), 279-288.

Mortier, P., Auerbach, R. P., Alonso, J., Bantjes, J., Benjet, C., Cuijpers, P.,et al. (2018a). Suicidal thoughts and behaviors among first-year college students: Results from the WMH-ICS Project. Journal of the American Academy of Child \& Adolescent Psychiatry, 57(4), 263-273.

Mortier, P., Demyttenaere, K., Auerbach, R. P., Cuijpers, P., Green, J. G., Kiekens, G., et al.(2017). First onset of suicidal thoughts and behaviours in college. Journal of Affective Disorders, 207, 291-299.

Moulds, M. L., Kandris, E., Williams, A. D., Lang, T., Yap, C., \& Hoffmeister, K. (2008). An investigation of the relationship between cognitive reactivity and rumination. Behavior Therapy, 39, 65-71.

Nolen-Hoeksema, S. (1991). Responses to depression and their effects on the duration of depressive episodes. Journal of Abnormal Psychology, 100(4), 569. 
Nolen-Hoeksema, S., Wisco, B. E., \& Lyubomirsky, S. (2008). Rethinking rumination. Perspectives on Psychological Science, 3(5), 400-424.

O’Connor, R.C., \& Noyce, R. (2008). Personality and cognitive processes: self-criticism and different types of rumination as predictors of suicidal ideation. Behaviour Research and Therapy, 46(3), 392-401.

Palmer Jr, C. J. (2004). Suicide attempt history, self-esteem, and suicide risk in a sample of 116 depressed voluntary inpatients. Psychological Reports, 95(3), 1092-1094.

Polanco-Roman, L., Jurska, J., Quiñones, V. \& Miranda, R. (2015). Brooding, Reflection, and Distraction: Relation to Non-Suicidal Self-Injury versus Suicide Attempts. Archives of Suicide Research, 19(3), 350-365.

Pompili, M., Gonda, X., Serafini, G., Innamorati, M., Sher, L., Amore, M.,.et al. (2013). Epidemiology of suicide in bipolar disorders: A systematic review of the literature. Bipolar Disorders, 15(5), 457-490.

Priester, M.J, \& Clum, G. A. (1992). Attributional style as a diathesis in predicting depression, hopelessness, and suicide ideation in college students. Journal of Psychopathology and Behavioral Assessment, 14 (2), 111-122.

Prigerson, H. G., Desai, R.A., Lui-Mares, W., \& Roseheck, R. A. ( 2003). Suicidal ideation and suicide attempts in homeless mentally ill persons: age-specific risks of substance abuse. Social Psychiatry and Psychiatry Epidemiology. 38, 213-19.

Ribeiro, J. D., Franklin, J. C., Fox, K. R., Bentley, K. H., Kleiman, E. M., Chang, B. P., et al. (2016). Self-injurious thoughts and behaviors as risk factors for future suicide ideation, attempts, and death: a meta-analysis of longitudinal studies. Psychological Medicine, 46, 225-236.

Rickelman, B. L., \& Houfek, J. F. (1995). Toward an interactional model of suicidal behaviors: Cognitive rigidity, attributional style, stress, hopelessness, and depression. Archives of psychiatric nursing, 9(3), 158-168.

Robbins, D., \& Alessi, N. (1985). Depressive symptoms and suicidal behavior in adolescents. American Journal of Psychiatry, 142, 588-592.

Rogers, M. L., \& Joiner, T. E. (2017). Rumination, suicidal ideation, and suicide attempts: A metaanalytic review. Review of General Psychology, 21(2), 132-142.

Rosenberg, M. (1965). Society and the adolescent self-image. Princeton, NJ: Princeton University Press.

Salman, S., Idrees, J., Hassan, F., Idrees, F., Arifullah, M., \& Badshah, S. (2014). Predictive Factors of Suicide Attempt and Non-Suicidal Self-Harm in Emergency Department. Emergence, 2(4), 166-169.

Samuelsson, M., Jokinen, J., Nordström, A. L., \& Nordström, P. (2006). CSF 5-HIAA, suicide intent and hopelessness in the prediction of early suicide in male high-risk suicide attempters. Acta Psychiatrica Scandinavica, 113, 44-47.

Sarkisian, K. L., Van Hulle, C. A., \& Hill Goldsmith., H. (2019). Brooding, Inattention, and Impulsivity as Predictors of Adolescent Suicidal Ideation. Journal of Abnormal Child Psychology, 47(2), 333-344.

Seo, H. J., Jung, Y. E., Jeong, S., Kim, J. B., Lee, M. S., Kim, J. M.,et al. (2014). Personality traits associated with suicidal behaviors in patients with depression: The CRESCEND study. Comprehensive Psychiatry, 55(5), 10851092.

Sheehan, D. V., Lecrubier, Y., Sheehan, K.H., Amorim, P., Janavs, J., Weiller, E., et al. (1998). The MiniInternational Neuropsychiatric Interview (M.I.N.I.): the development and validation of a structured diagnostic psychiatric interview for DSM-IV and ICD-10. The Journal of Clinical Psychiatry, 59(20), 22-33, quiz 34-57.

Stange, J. P., Hamilton, J. L., Burke, T. A., Kleiman, E. M., O’Garro-Moore, J. K., Seligman, N. D., et al. (2015). Negative cognitive styles synergistically predict suicidal ideation in bipolar spectrum disorders: a 3-year prospective study. Psychiatry Research, 226(1), 162-168.

Steeg, S., Haigh, M., Webb, R. T., Kapur, N., Awenat, Y., Gooding, P., .et al. (2016). The exacerbating influence of hopelessness on other known risk factors for repeat self-harm and suicide. Journal of affective disorders, 190, 522-528.

Su, M. H., Chen, H. C., Lu, M. L., Feng, J., Chen, I.M., Wu, C.S., et al. (2018). Risk profiles of personality traits for suicidality among mood disorder patients and community controls. Acta Psychiatrica Scandinavica 137, 3038.

Treynor, W., Gonzalez, R., \& Nolen-Hoeksema, S. (2003). Rumination reconsidered: A psychometric analysis. Cognitive Therapy and Research, 27 (3), 247-259.

Turkish Statistical Institute. Suicide Statistics 2015. Bulletin of TSI: 215216;2016. Available online: http://www. tuik. gov.tr/ PreHaberBultenleri. do?id=21516.

Valtonen, H., Suominen, K., Mantere, O., Leppamaki, S., Arvilommi, P., \& Isometsa, E.T. (2005). Suicidal ideation and attempts in bipolar I and II disorders. Journal of Clinical Psychiatry, 66(11), 1456-1462.

Van der Does, A. J. W., \& Williams, J. M. G. (2003). Leiden Index of Depression Sensitivity-Revised (LEIDSR). Leiden University. Retrieved November $1, \quad$ 2015, from http://www.dousa.nl/publications depression.htm\#LEIDS.

Van der Does, W. (2002). Cognitive reactivity to sad mood: structure and validity of a new measure. Behaviour Research and Therapy, 40(1), 105-119.

Vella, M. L., Persic, S., \& Lester, D. (1996). Does self-esteem predict suicidality after controls for depression?.Psychological reports, 79(3), 1178-1178. 
Velting, D. M. (1999). Suicidal ideation and the five-factor model of personality. Personality and Individual Differences, 27(5), 943-952.

Voracek, M. (2009). Big Five personality factors and suicide rates in the United States: A state-level analysis. Perceptual and motor skills, 109(1), 208-212.

Waldvogel, J. L., Rueter, M., \& Oberg, C. N. (2008). Adolescent suicide: Risk factors and prevention strategies. Current Problems in Pediatric and Adolescent Health Care, 38, 110-125.

Washburn, J. J., Richardt, S.L., Styer, D.M., Gebhardt, M., Juzwin, K.R., Yourek, A., et al. (2012). Psychotherapeutic approaches to non-suicidal self-injury in adolescents. Child and Adolescent Psychiatry and Mental Health, 6(14), 1-8.

Wild, L. G., Flisher, A. J., \& Lombard, C. (2004). Suicidal ideation and attempts in adolescents: Associations with depression and six domains of self-esteem. Journal of Adolescence, 27, 611-624.

Wongpakaran, N., Wongpakaran, T., Kittipodjanasit, A., Chompoosri, P., Kuntawong, P., \& Wedding, D. (2019). Predictive factors for suicidal attempts: A case-control study. Perspectives in Psychiatric Care, 55(4), 667-672.

World Health Organization (2014). Preventing suicide: a global imperative. Luxembourg: World Health Organization, 9-45. Retrieved from https://www.who.int/mental_health/suicideprevention/world_report_2014/en/.

World Health Organization. (2012). Public health action for the prevention of suicide: A framework. Geneva, Switzerland. Retrieved from https://www.who.int/mental_health/publications/prevention_suicide_2012/en/.

Zigmond, A. S., \& Snaith, R. P. (1983). The hospital anxiety and depression scale. Acta Psychiatrica Scandinavica, 67(6), 361-370. 
Table 1 Demographic features and group differences for scale scores between groups that did or did not attempt suicide.

\begin{tabular}{|c|c|c|c|c|c|}
\hline Variable & $\begin{array}{l}\text { All participants } \\
\text { Mean(SD)/n(\%) }\end{array}$ & $\begin{array}{l}\text { Previous } \\
\text { Suicide } \\
\text { Attempt (Yes) } \\
\text { Mean(SD)/n(\%) }\end{array}$ & $\begin{array}{l}\text { Previous } \\
\text { Suicide } \\
\text { Attempt (No) } \\
\text { Mean(SD)/n(\%) }\end{array}$ & $\mathrm{t}(\mathrm{df}) / \mathrm{X}^{2}(\mathrm{df})$ & $\mathrm{P}$ \\
\hline Age & $19,59( \pm 6,27)$ & $20,94( \pm 7,96)$ & $19,44( \pm 6,06)$ & $-1,31(343)$ & 0,188 \\
\hline $\begin{array}{l}\text { Gender } \\
\text { (Female) }\end{array}$ & $258(72,7 \%)$ & $21(61,8 \%)$ & $237(73,8 \%)$ & $2,25(1)$ & 0,133 \\
\hline $\begin{array}{l}\text { Marital Status } \\
\text { (Single) }\end{array}$ & $345(97,2 \%)$ & $30(88,2 \%)$ & $315(98,1 \%)$ & $10,99(1)$ & 0,001 \\
\hline $\begin{array}{l}\text { Family History } \\
\text { (Yes) }\end{array}$ & $40(11,3 \%)$ & $12(35,3 \%)$ & $28(8,7 \%)$ & $21,71(1)$ & $0 ; 000$ \\
\hline $\begin{array}{l}\text { Previous } \\
\text { Psychiatric } \\
\text { Treatment } \\
\text { History (Yes) } \\
\end{array}$ & $40(11,3 \%)$ & $11(33,3 \%)$ & $29(9,1 \%)$ & $17,53(1)$ & 0,000 \\
\hline $\begin{array}{l}\text { Previous } \\
\text { Hospitalization } \\
\text { (Yes) }\end{array}$ & $4(1,1 \%)$ & $4(1,3 \%)$ & $0(0,0 \%)$ & $0,43(1)$ & 0,512 \\
\hline $\begin{array}{l}\text { Medical } \\
\text { Disorder (Yes) }\end{array}$ & $28(7,9 \%)$ & $7(20,6 \%)$ & $21(20,6 \%)$ & $77,87(3)$ & 0,000 \\
\hline Social support & $3,82( \pm 1,09)$ & $3,08( \pm 1,26)$ & $3,90( \pm 1,05)$ & $4,20(353)$ & 0,000 \\
\hline $\begin{array}{l}\text { Childhood } \\
\text { trauma }\end{array}$ & $1,60( \pm 1,35)$ & $2,00( \pm 1,43)$ & $1,56( \pm 1,34)$ & $-1,80(353)$ & 0,072 \\
\hline Quality of life & $3,65( \pm 0,92)$ & $3,20( \pm 1,09)$ & $3,70( \pm 0,89)$ & $3,02(353)$ & 0,003 \\
\hline HADS_Anx & $18,50( \pm 2,60)$ & $17,97( \pm 2,94)$ & $18,56( \pm 2,56)$ & $1,26(352)$ & 0,207 \\
\hline HADS_Dep & $16,05( \pm 2,01)$ & $16,64( \pm 3,06)$ & $15,99( \pm 1,86)$ & $-1,80(353)$ & 0,072 \\
\hline RRSBROOD & $11,34( \pm 2,86)$ & $12,58( \pm 3,66)$ & $11,21( \pm 2,74)$ & $-2,67(353)$ & 0,008 \\
\hline RRSREFLECT & $11,44( \pm 2,87)$ & $12,29( \pm 3,69)$ & $11,35( \pm 2,76)$ & $-1,81(352)$ & 0,070 \\
\hline RRS & $22,78( \pm 5,14)$ & $24,88( \pm 6,83)$ & $22,56( \pm 4,88)$ & $-2,51(352)$ & 0,012 \\
\hline $\mathrm{HOP}$ & $8,02( \pm 3,82)$ & $8,11( \pm 3,91)$ & $8,01( \pm 3,81)$ & $-0,15(353)$ & 0,878 \\
\hline ACC & $8,74( \pm 3,49)$ & $9,82( \pm 4,34)$ & $8,62( \pm 3,38)$ & $-1,90(353)$ & 0,058 \\
\hline AGG & $10,22( \pm 4,52)$ & $11,94( \pm 4,38)$ & $10,04( \pm, 50)$ & $-2,33(353)$ & 0,020 \\
\hline $\mathrm{CON}$ & $10,28( \pm 3,79)$ & $10,79( \pm 3,54)$ & $10,23( \pm 3,81)$ & $-0,82(353)$ & 0,412 \\
\hline RAV & $12,05( \pm 3,92)$ & $11,58( \pm 4,38)$ & $12,10( \pm 3,88)$ & $0,73(353)$ & 0,464 \\
\hline RUM & $12,19( \pm 4,65)$ & $11,44( \pm 4,36)$ & $12,27( \pm 4,68)$ & $0,99(353)$ & 0,320 \\
\hline
\end{tabular}




\begin{tabular}{|l|l|l|l|l|l|}
\hline LEIDS-R & $61,53( \pm 18,02)$ & $63,70( \pm 16,95)$ & $61,30( \pm 18,14)$ & $-0,73(353)$ & 0,460 \\
\hline TIPI_E & $4,57( \pm 1,53)$ & $4,64( \pm 1,79)$ & $4,56( \pm 1,50)$ & $-0,28(349)$ & 0,775 \\
\hline TIPI_A & $5,02( \pm 1,27)$ & $4,48( \pm 1,55)$ & $5,08( \pm 1,23)$ & $2,63(350)$ & 0,009 \\
\hline TIPI_C & $5,08( \pm 1,37)$ & $5,05( \pm 1,41)$ & $5,08( \pm 1,37)$ & $0,11(349)$ & 0,911 \\
\hline TIPI_ES & $4,35( \pm 1,28)$ & $4,01( \pm 1,41)$ & $4,38( \pm 1,27)$ & $1,61(349)$ & 0,107 \\
\hline TIPI_O & $4,63( \pm 1,26)$ & $4,61( \pm 1,42)$ & $4,63( \pm 1,24)$ & $0,09(350)$ & 0,928 \\
\hline BHS & $5,85( \pm 4,56)$ & $7,94( \pm 5,63)$ & $5,62( \pm 4,38)$ & $-2,83(347)$ & 0,005 \\
\hline RSES & $1,08( \pm 0,77)$ & $0,91( \pm 1,01)$ & $1,10( \pm 0,74)$ & $1,37(353)$ & 0,171 \\
\hline CSQ_Inter & $45,61( \pm 5,27)$ & $47,12( \pm 7,88)$ & $45,44( \pm 4,89)$ & $-1,73(331)$ & 0,084 \\
\hline CSQ_Glob & $41,17( \pm 6,62)$ & $45,50( \pm 9,17)$ & $40,70( \pm 6,11)$ & $-4,10(340)$ & 0,000 \\
\hline CSQ_Stab & $39,25( \pm 8,27)$ & $45,26( \pm 9,90)$ & $38,60( \pm 7,82)$ & $-4,58(349)$ & 0,000 \\
\hline CSQ_NeqC & $21,19( \pm 3,86)$ & $22,24( \pm 3,26)$ & $21,08( \pm 3,90)$ & $-1,63(350)$ & 0,102 \\
\hline CSQ_SelfW & $44,57( \pm 8,90)$ & $46,58( \pm 9,97)$ & $44,35( \pm 8,76)$ & $-1,39(349)$ & 0,165 \\
\hline CSQ & $191,63( \pm 24,68)$ & $207,40( \pm 32,78)$ & $189,88( \pm 23,02)$ & $-3,89(319)$ & 0,000 \\
\hline
\end{tabular}

Note.HADS_Anx, Hospital Anxiety and Depression Scale_Anxiety; HADS_Dep, Hospital Anxiety and Depression Scale_Depression; RRS,Ruminative Response Scale; RRSBROOD, Ruminative Response Scale_Brooding, RRSREFLECT, Ruminative Response Scale_Reflection, HOP, Hopelessness, ACC, Acceptence,AGG, Aggression, CON, Control; RAV, Risk Aversion; RUM, Rumination; LEIDSR, Leiden Index of Depression Sensitivity-Revised;TIPI, Ten-Item Personality Inventory; E, Extraversion; A, Agreeableness; C, Conscientiousness; ES, Emotional Stability; O, Openness; BHS, Beck Hoplessness Scale; RSES, Rosenberg Self-Esteem Scale; CSQ, Cognitive Style Quessionaire; CSQ_Inter, Cognitive Style Quessionaire_Internal; CSQ_Glob, Cognitive Style Quessionaire_Global;CSQ_Stab, Cognitive Style Quessionaire_Stable; CSQ_NeqC, Cognitive Style Quessionaire_Negative Consequences;CSQ_SelfW, Cognitive Style Quessionaire_Self Worth. 
Table 2. Intercorrelations for suicide attempt and correlates

\begin{tabular}{|c|c|c|c|c|c|c|c|c|c|c|c|c|c|c|c|}
\hline Variable & 1 & 2 & 3 & 4 & 5 & 6 & 7 & 8 & 9 & 10 & 11 & 12 & 13 & 14 & 15 \\
\hline $\begin{array}{l}\text { 1. Suicide } \\
\text { attempt }\end{array}$ & - & & & & & & & & & & & & & & \\
\hline 2. Age & .071 & - & & & & & & & & & & & & & \\
\hline 3. Sex & -.080 & .040 & - & & & & & & & & & & & & \\
\hline $\begin{array}{ll}4 . & \text { HADS } \\
& \text { Depression }\end{array}$ & -.067 & $.117^{*}$ & .081 & - & & & & & & & & & & & \\
\hline $\begin{array}{ll}5 . & \text { HADS } \\
& \text { Anxiety } \\
\end{array}$ & .096 & .020 & .014 & .075 & - & & & & & & & & & & \\
\hline 6. TIPI-E & .015 & -.104 & .001 & .076 & .081 & - & & & & & & & & & \\
\hline 7. TIPI-A & $\begin{array}{c}- \\
.139 * *\end{array}$ & .005 & $.162 * *$ & .097 & $.143 * *$ & $.202 * *$ & - & & & & & & & & \\
\hline 8. TIPI-C & -.006 & .001 & $.112 *$ & $.133^{*}$ & .019 & $.401 * *$ & $.348 * *$ & - & & & & & & & \\
\hline 9. TIPI-ES & -.086 & .056 & .001 & $.270 * *$ & -.087 & .045 & $.283 * *$ & $.198 * *$ & - & & & & & & \\
\hline 10. TIPI-O & -.005 & -.017 & .038 & .068 & .045 & $.272 * *$ & $.216^{* *}$ & $.308 * *$ & -.019 & - & & & & & \\
\hline 11. RRS & $.133^{*}$ & -.076 & .004 & $.339 * *$ & -.029 & $-.115^{*}$ & $-.130 *$ & $\begin{array}{c}- \\
.173^{* *}\end{array}$ & $.295 * *$ & .032 & - & & & & \\
\hline 12. LEIDS-R & .039 & -.023 & -.060 & $.318 * *$ & .001 & -.061 & $-.135^{*}$ & $.204 * *$ & $\begin{array}{c}- \\
.175^{* *}\end{array}$ & -.049 & $.341 * *$ & - & & & \\
\hline 13. BHS & $.151 * *$ & .027 & $.240 * *$ & $.277 * *$ & $.117 *$ & $.224 * *$ & $.212^{-} * *$ & $.392^{-} * *$ & $\begin{array}{c}- \\
.191 * * \\
\end{array}$ & $.224 * *$ & $.228 * *$ & $.235 * *$ & - & & \\
\hline 14. RSES & -.073 & -.099 & $-.128 *$ & $.271 * *$ & -.053 & $.262 * *$ & -.071 & $.258 * *$ & $.199 * *$ & $.121^{*}$ & $.238 * *$ & $.239 * *$ & $.305 * *$ & - & \\
\hline 15. CSQ-SF & $.213 * *$ & -.006 & $.211 * *$ & $.145^{* *}$ & $.136^{*}$ & -.090 & $\begin{array}{c}- \\
.145^{* * *}\end{array}$ & $\begin{array}{c}- \\
.213^{* *}\end{array}$ & $.217 * *$ & $-.139 *$ & $.140^{*}$ & $.339 * *$ & $.384 * *$ & $.121 *$ & - \\
\hline
\end{tabular}

Note. Suicide attempt coded as $1=$ Yes, $0=$ No; sex coded as $1=$ Female, $0=$ Male. HADS, Hospital Anxiety and Depression Scale; TIPI, Ten-Item Personality Inventory; E, Extraversion; A, Agreeableness; C, Conscientiousness; ES, Emotional Stability; O, Openness; RRS, Ruminative Response Scale; LEIDS-R, Leiden Index of Depression Sensitivity - Revised; BHS, Beck Hopelessness Scale; RSES, Rosenberg Self Esteem Scale; CSQ-SF, Cognitive Style Questionnaire - Short Form. * $p<0.05 ; * * p<0.01$. 
Table 3. Last step of the logistic regression analysis and correlates of suicide attempt.

\begin{tabular}{|l|c|c|c|c|c|c|}
\hline Variable & $B$ & $S E$ & OR & $95 \%$ CI & $\begin{array}{c}\text { Wald } \\
\text { statistic }\end{array}$ & $p$ \\
\hline RRS & 0.074 & 0.040 & 1.077 & $1.005,1.166$ & 3.372 & 0.046 \\
\hline TIPI-A & -0.508 & 0.182 & 0.602 & $0.421,0.859$ & 7.802 & 0.005 \\
\hline TIPI-C & 0.356 & 0.192 & 1.427 & $0.979,2.080$ & 3.423 & 0.064 \\
\hline BHS & 0.104 & 0.048 & 1.109 & $1.009,1.220$ & 4.578 & 0.032 \\
\hline RSES & -0.696 & 0.293 & 0.499 & $0.281,0.885$ & 5.649 & 0.017 \\
\hline CSQ-SF & 0.022 & 0.009 & 1.023 & $1.004,1.041$ & 5.908 & 0.015 \\
\hline
\end{tabular}

Note. $\mathrm{CI}=$ confidence interval for odds ratio $(O R)$. TIPI, Ten-Item Personality Inventory; A, Agreeableness; C, Conscientiousness; RRS, Ruminative Response Scale; BHS, Beck Hopelessness Scale; RSES, Rosenberg Self Esteem Scale; CSQ-SF, Cognitive Style Questionnaire - Short Form. 